\title{
CDC and YMCA: a promising partnership for delivering fall prevention programing
}

\author{
Heidi Ehrenreich $^{1}$, Maureen Pike ${ }^{2}$, Katherine Hohman ${ }^{2}$, Margaret Kaniewski $^{1}$, Matt Longjohn ${ }^{2}$, \\ Gaya Myers ${ }^{1}$ and Robin Lee ${ }^{1}$
}

1 Division of Unintentional Injury Prevention, National Center for Injury Prevention and Control, Centers for Disease Control and Prevention, Atlanta, GA, USA

${ }^{2}$ YMCA of the USA, Chicago, IL, USA

${ }^{*}$ Correspondence: vza7@cdc.gov

Edited by:

Matthew Lee Smith, The University of Georgia, USA

Reviewed by:

Heather Honoré Goltz, University of Houston-Downtown, USA

Keywords: fall prevention, Tai Chi, community-based programs, partnerships, dissemination

\section{OLDER ADULT FALLS}

Falls threaten the independence of adults aged 65 years and older. In the U.S., one in three older adults fall annually, causing significant disability and reduced quality of life (1). The high prevalence of falls, coupled with more than $\$ 30$ billion in direct medical costs (2) has created a critical need for effective older adult fall prevention programs. As the nation's public health agency, the Centers for Disease Control and Prevention (CDC) is committed to identifying ways to reduce the burden of older adult falls. In this commentary, we describe a promising approach to reach older adults with effective interventions by partnering with the YMCA to deliver communitybased fall prevention programs.

\section{IMPLEMENTATION OF EFFECTIVE COMMUNITY FALL PREVENTION PROGRAMS}

Centers for Disease Control and Prevention has produced several guides dedicated to fall prevention programing and delivery. The CDC Compendium of Effective Fall Interventions is intended to help public health practitioners use the best scientific evidence to effectively address falls among older adults in the community (3).

The Compendium describes 22 scientifically tested interventions for use by public health practitioners, aging service providers, and others. In addition, CDC developed a how-to guide for communitybased organizations seeking to develop, implement, and evaluate their own effective fall prevention programs (4).

While federal and state public health agencies have used CDC's guide to implement fall prevention programs, the information about effective programs does not always reach the intended audience (5). This is largely due to the lack of local infrastructure needed to deliver communitybased programs (6). Developing and maintaining the necessary organizational infrastructure can be time consuming and costly, limiting program sustainability. A recent systematic review revealed that stable financial program support, integrated programing, and the ability to make program adaptations were major factors that sustained successful fall prevention programs (7).

YMCA's robust infrastructure for program delivery, large membership base, and local credibility offer strong potential for building successful and wide-reaching public health programing. The marketing literature supports the use of these types of distribution channels to improve the adoption and implementation of evidencebased programs (8). For these reasons, CDC is pursuing partnerships with organizations such as YMCAs to help implement effective fall prevention programs.

\section{PARTNERING WITH THE YMCA TO SCALE-UP SUCCESSFUL PUBLIC HEALTH PROGRAMS}

YMCAs are independent but federated organizations working to spread health and wellness in their communities. YMCAs offer classes for all ages, all skill levels, and all interests. As a national resource center, YMCA of the USA (Y-USA) supports over 2,600 YMCAs located across 10,000 U.S. neighborhoods and with 20.6 million members (http://www.ymca.net).

Y-USA has a history of collaborating on national public health initiatives $(9,10)$. YUSA partnered with CDC and the National Association of Chronic Disease Directors to disseminate EnhanceFitness, an evidencebased exercise program for older adults. In the program, trained YMCA fitness staff and volunteers lead a comprehensive exercise routine shown to increase physical, mental, and social functioning in older adults (11). In the first year of this partnership, the program reached 2,000 older adults at 41 YMCAs. In another initiative, 157 YMCAs partnered with the LIVESTRONG Foundation for extensive training as hubs of support for cancer survivors. To date, over 21,000 survivors have been served by this initiative. Finally, CDC partnered with Y-USA to reach over 19,000 participants at 128 YMCAs to expand its evidence-based National Diabetes Prevention Program to participating communities (12). As part of this CDC-led program, YMCAs have trained their wellness instructors as "lifestyle coaches" to implement lifestyle-change programs focused on participants losing weight, being physically active, and coping with stress.

\section{YMCA ADAPTS CDC'S OLDER ADULT FALL PREVENTION PROGRAM}

Motivated by the success of the National Diabetes Prevention Program, CDC initiated a similar strategy to implement an evidence-based older adult fall prevention program using the YMCA infrastructure. With funding from the CDC, YUSA licensed the rights to the Tai Chi Moving for Better Balance fall prevention program (13) and adapted the program to fit the YMCA training system. Y-USA reintroduced the program under the name, Y-Moving for Better Balance (Y-MFBB) and contracted with the program's creator to train YMCA Faculty Trainers as Y-MFBB instructors. As of September 2013, 287 


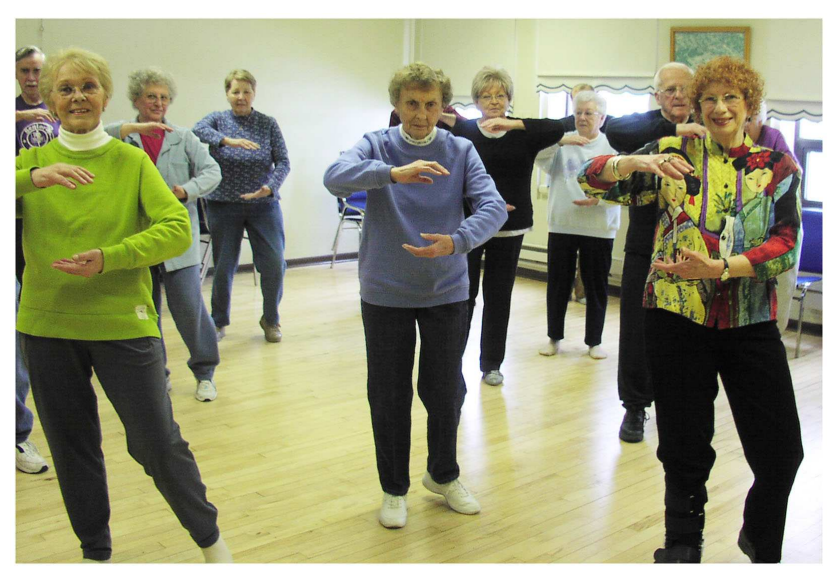

FIGURE 1 | Y-MFBB Class in Broome County, New York.

Y-MFBB instructors have been trained. To encourage implementation of Y-MFBB locally, Y-USA awarded 131 YMCAs grants of $\$ 1000$ each to hold instructor trainings and initiate Y-MFBB classes.

In fall 2013, the Y-USA interviewed staff directors from 8 of the 75 YMCAs offering Y-MFBB in the last year to gather lessons learned about local Y-MFBB implementation. After approximately 17 months, these 8 YMCAs had reached 706 participants. Most participants were women, aged 65 years and older, and YMCA members (see Figure 1 depicting Y-MFBB participants). Participants reported discovering the Y-MFBB program through YMCA advertising, local community organizations, and from medical professionals. Cost to participate ranged from no additional charge for members to $\$ 70$ per 12 -week session, or approximately $\$ 3$ per class, for a YMCA offering the program at an off-site facility. Four YMCAs reported an implementation cost of $\$ 386$ per 12-week session, based mainly on instructor time.

Overall, staff directors determined that fall prevention programing fit well with YMCA's health and wellness mission, citing two main reasons for offering Y-MFBB: (1) the growing number of older adult members; and (2) the high incidence of falls among them. However, Y-MFBB instructors also need the opportunity to check program fidelity and offer progressively more challenging classes. With more Y-MFBB instructors and training, the directors are considering placing Y-MFBB into a larger portfolio of falls prevention programing at their sites. CDC is currently supporting the development of a national Y-MFBB rollout plan based on further research into program and implementation effectiveness.

\section{NEXT STEPS}

While CDC and state public health agencies have the tools to assess and address public health problems, community-based organizations are often tasked with delivering programs. The YMCA has been an important partner for scaling up the CDC fall prevention program to a wider and more diverse audience. This example of leveraging partnerships with organizations that already have a robust infrastructure in place for large-scale program delivery is critical for population-level gains. CDC will continue to work with organizations such as the YMCA to increase the availability of Y-MFBB and other evidence-based fall prevention programs to reduce fall risk among older adults.

\section{ACKNOWLEDGMENTS}

We sincerely thank the Program Directors from the local YMCAs who engaged in in-depth interviews to describe their offerings of the Y-Moving for Better Balance program. We also thank Dr. Erin Parker for her thoughtful review and suggestions. This work was supported in part by an appointment to the Research Participation Program at the Centers for Disease Control and Prevention (CDC) administered by the Oak Ridge Institute for Science and Education through an interagency agreement between the U.S. Department of Energy and CDC. The findings and conclusions in this report are those of the authors and do not necessarily represent the official position of the Centers for Disease Control and Prevention.

\section{REFERENCES}

1. Tromp AM, Pluijm SMF, Smit JH, Deeg DJH, Bouter LM, Lips P. Fall-risk screening test: a prospective study on predictors for falls in community-dwelling elderly. J Clin Epidemiol (2001) 54(8):837-44. doi:10.1016/S08954356(01)00349-3

2. Stevens JA, Corso PS, Finkelstein EA, Miller TR. The costs of fatal and non-fatal falls among older adults. Inj Prev (2006) 12(5):290-5. doi:10.1136/ ip.2005.011015

3. Stevens JA. Compendium of Effective Fall Interventions: What Works for Community-Dwelling Older Adults. Atlanta, GA: Centers for Disease Control and Prevention, National Center for Injury Prevention (2010).

4. Centers for Disease Control and Prevention (CDC). National Center for Injury Prevention and Control. Preventing Falls: How to Develop Community-based Fall Prevention Programs for Older Adults. Atlanta, GA: Centers for Disease Control and Prevention (2008).

5. Durlak J, DuPre E. Implementation matters: a review of research on the influence of implementation on program outcomes and the factors affecting implementation. Am J Community Psychol (2008) 41(3-4):327-50. doi:10.1007/s10464008-9165-0

6. Fixsen D, Scott V, Blase K, Naoom S, Wagar L. When evidence is not enough: the challenge of implementing fall prevention strategies. J Safety Res (2011) 42(6):419-22. doi:10.1016/j.jsr.2011. 10.002

7. Lovarini M, Clemson L, Dean C. Sustainability of community-based fall prevention programs: a systematic review. J Safety Res (2013) 47(0):9-17. doi:10.1016/j.jsr.2013.08.004

8. Maibach E, Van Duyn MAS, Bloodgood B. A marketing perspective on disseminating evidencebased approaches to disease prevention and health promotion. Prev Chronic Dis (2006) 3(3):1-11. doi:10.5888/pcd9.110081

9. Adamson K, Shepard D, Easton A, Jones ES. The YMCA/steps community collaboratives, 20042008. Prev Chronic Dis (2009) 6(3):1-5.

10. Ackermann RT, Marrero DG. Adapting the diabetes prevention program lifestyle intervention for delivery in the community: the YMCA model. Diabetes Educ (2007) 33(1):69-78. doi:10.1177/ 0145721706297743

11. Belza B, Shumway Cook A, Phelan E, Williams B, Snyder S. The effects of a communitybased exercise program on function and health in older adults: the EnhanceFitness program. J Appl Gerontol (2006) 25(4):291-306. doi:10. 1177/0733464806290934

12. Murphy D, Chapel T, Clark C. Moving diabetes care from science to practice: the evolution of the national diabetes prevention and control program. 
Ann Intern Med (2004) 140(11):978-84. doi:10. 7326/0003-4819-140-11-200406010-00040

13. Li F, Harmer P, Mack KA, Sleet D, Fisher KJ, Kohn MA, et al. Tai Chi: moving for better balance: development of a community-based falls prevention program. J Phys Act Health (2008) 5(3): $445-55$.

Conflict of Interest Statement: The authors declare that the research was conducted in the absence of any commercial or financial relationships that could be construed as a potential conflict of interest.

This paper is included in the Research Topic, "EvidenceBased Programming for Older Adults." This Research Topic received partial funding from multiple government and private organizations/agencies; however, the views, findings, and conclusions in these articles are those of the authors and do not necessarily represent the official position of these organizations/agencies. All papers published in the Research Topic received peer review from members of the Frontiers in Public Health (Public Health Education and Promotion section) panel of Review Editors. Because this Research Topic represents work closely associated with a nationwide evidence-based movement in the US, many of the authors and/or Review Editors may have worked together previously in some fashion. Review Editors were purposively selected based on their expertise with evaluation and/or evidence-based programming for older adults. Review Editors were independent of named authors on any given article published in this volume.

Received: 16 June 2014; accepted: 28 October 2014; published online: 27 April 2015.
Citation: Ehrenreich H, Pike M, Hohman K, Kaniewski $M$, Longjohn M, Myers G and Lee R (2015) CDC and YMCA: a promising partnership for delivering fall prevention programing. Front. Public Health 2:235. doi: 10.3389/fpubh.2014.00235

This article was submitted to Public Health Education and Promotion, a section of the journal Frontiers in Public Health.

Copyright (c) 2015 Ehrenreich, Pike, Hohman, Kaniewski, Longjohn, Myers and Lee. This is an openaccess article distributed under the terms of the Creative Commons Attribution License (CC BY). The use, distribution or reproduction in other forums is permitted, provided the original author(s) or licensor are credited and that the original publication in this journal is cited, in accordance with accepted academic practice. No use, distribution or reproduction is permitted which does not comply with these terms. 